\title{
Determination of dissolved nitric oxide in coastal waters of the Yellow Sea off Qingdao
}

\author{
Chun-Ying Liu ${ }^{1,2,3}$, Wei-Hua Feng ${ }^{1,4}$, Ye Tian ${ }^{1}$, Gui-Peng Yang ${ }^{1,2,3}$, Pei-Feng Li ${ }^{1}$, and Hermann W. Bange \\ ${ }^{1}$ College of Chemistry and Chemical Engineering, Ocean University of China, Qingdao, 266100, China \\ ${ }^{2}$ Laboratory for Marine Ecology and Environmental Science, Qingdao National Laboratory for Marine Science \\ and Technology, Qingdao, 266071, China \\ ${ }^{3}$ Key Laboratory of Marine Chemistry Theory and Technology, Ministry of Education, Qingdao, 266100, China \\ ${ }^{4}$ Key Laboratory of Engineering Oceanography, Second Institute of Oceanography, SOA, Hangzhou, 310012, China \\ ${ }^{5}$ GEOMAR Helmholtz-Zentrum für Ozeanforschung Kiel, 24105 Kiel, Germany
}

Correspondence to: Gui-Peng Yang (gpyang@ouc.edu.cn)

Received: 5 March 2017 - Discussion started: 3 April 2017

Revised: 15 July 2017 - Accepted: 27 July 2017 - Published: 29 August 2017

\begin{abstract}
We developed a new method for the determination of dissolved nitric oxide (NO) in discrete seawater samples based on the combination of a purge-and-trap setup and a fluorometric detection of NO. 2,3-diaminonaphthalene (DAN) reacts with $\mathrm{NO}$ in seawater to form the highly fluorescent 2,3naphthotriazole (NAT). The fluorescence intensity was linear for $\mathrm{NO}$ concentrations in the range from 0.14 to $19 \mathrm{nmol} \mathrm{L}^{-1}$. We determined a detection limit of $0.068 \mathrm{nmol} \mathrm{L}^{-1}$, an average recovery coefficient of $83.8 \%(80.2-90.0 \%)$, and a relative standard deviation of $\pm 7.2 \%$. With our method we determined for the first time the temporal and spatial distributions of NO surface concentrations in coastal waters of the Yellow Sea off Qingdao and in Jiaozhou Bay during a cruise in November 2009. The concentrations of NO varied from below the detection limit to $0.50 \mathrm{nmol} \mathrm{L}^{-1}$ with an average of $0.26 \pm 0.14 \mathrm{nmol} \mathrm{L}^{-1}$. NO surface concentrations were generally enhanced significantly during daytime, implying that $\mathrm{NO}$ formation processes such as $\mathrm{NO}_{2}^{-}$photolysis are much higher during daytime than chemical NO consumption, which, in turn, lead to a significant decrease in $\mathrm{NO}$ concentrations during nighttime. In general, NO surface concentrations and measured NO production rates were higher compared to previously reported measurements. This might be caused by the high $\mathrm{NO}_{2}^{-}$surface concentrations encountered during the cruise. Moreover, additional measurements of NO production rates implied that the occurrence of particles and a temperature increase can enhance NO production rates. With the method introduced here, we have a reli-
\end{abstract}

able and comparably easy to use method at hand to measure oceanic NO surface concentrations, which can be used to decipher both its temporal and spatial distributions as well as its biogeochemical pathways in the oceans.

\section{Introduction}

As a reactive atmospheric trace gas, nitric oxide (NO) plays important roles in tropospheric chemistry: it is a key player in the formation of acid rain and ozone (Williams et al., 1992; Lee et al., 1997; Mazzeo et al., 2005). NO is an intermediate of both the terrestrial and marine nitrogen cycle (Ward and Zafiriou, 1988; Canfield et al., 2010; Chen et al., 2010; Thamdrup, 2012; Voss et al., 2013). It has a variety of sources in seawater, including nitrite photolysis and various microbial processes such as denitrification, anammox and dissimilatory nitrate reduction to ammonia (Law, 2001; Schreiber et al., 2012; Martens-Habbena et al., 2015). Because of its chemical reactivity, $\mathrm{NO}$ usually does not accumulate in large amounts in seawater and the ocean as a source of atmospheric NO is, therefore, negligible in a global context (Zehr and Ward, 2002; Bange, 2008). Moreover, NO was found to have significant effects on the growth of marine algae (Zhang et al., 2005; Liu et al., 2004, 2005, 2006, 2014). To this end, the determination of the spatial and temporal distributions of NO in the ocean, and deciphering its oceanic production processes and their major influencing factors is essential to 
improve our understanding of the biogeochemical cycling of NO in the ocean.

Because of its low concentrations in seawater caused by its fast diffusion and high chemical reactivity, measurements of NO in seawater are very difficult. Therefore, there are only a few methods available to determine NO (Hetrick and Schoenfisch, 2009) (see Table 1). The electrochemical method using sensors in seawater medium achieved a detection limit of $42 \mathrm{nmol} \mathrm{L}^{-1}$ (Xing et al., 2005; Zhang et al., 2005). Olasehinde et al. (2009) developed a method for the determination of photochemically generated $\mathrm{NO}$ in natural waters adopting 4,5-diaminofluorescein as a probe compound and a measurement using reversed-phase highperformance liquid chromatography (HPLC) with a fluorescence detector. The NO concentrations and signal intensities exhibited a good linearity correlation over the range of $0.025-10 \mathrm{nmol} \mathrm{L}^{-1}$ triazolofluorescein. Zafiriou and McFarland (1980) determined the NO concentration of seawater by using a flow system to equilibrate the seawater samples with a gas stream coupled to a chemiluminescence detector. They report an analytical precision of $\pm 3 \%$ and an accuracy of $\pm 20 \%$. More recently, Lutterbeck and Bange (2015) developed an improved method of a chemiluminescence NO analyzer connected to a stripping unit, and the limit of detection was $0.25 \mathrm{nmol} \mathrm{L}^{-1}$ using a $20 \mathrm{~mL}$ seawater sample volume. Until now only these two chemiluminescence methods have been applied successfully to determine NO concentrations in seawater samples. The $\mathrm{N}$-nitrosation of 2,3diaminonaphthalene (DAN) results in the highly fluorescent 2,3-naphthotriazole (NAT), which could be used to detect $\mathrm{NO}$ concentrations as low as $10 \mathrm{nmol} \mathrm{L}^{-1}$ (Miles et al., 1995). We adopted this method for seawater medium instead of $\mathrm{NaOH}$ medium and the calibration curve exhibited linearity over the concentration range of $1.4-1400 \mathrm{nmol} \mathrm{L}^{-1} \mathrm{NO}$ (Liu et al., 2009). However, this assay cannot be used to detect trace levels of NO in seawater samples directly.

In this paper, we describe a modified spectrofluorometric method using a purge-and-trap technique, which can be used to quantify NO in seawater samples. This method was applied in a first field study on the distribution and production rates of dissolved NO in coastal waters of the Yellow Sea off Qingdao and Jiaozhou Bay.

\section{Materials and methods}

\subsection{Instrumental setup}

The analytical system (Fig. 1) consists of a degassing column to purge NO from seawater samples, a reaction chamber where NO reacts to form a fluorescent compound, and a fluorescence spectrophotometer (F-4500, Hitachi Co., Japan). The $800 \mathrm{~mL}$ degassing column (6) has a sodium silicate bonded sand core at the bottom to disperse the nitrogen $\left(\mathrm{N}_{2}\right)$ purge gas stream. There are four ports on the column: (a) a

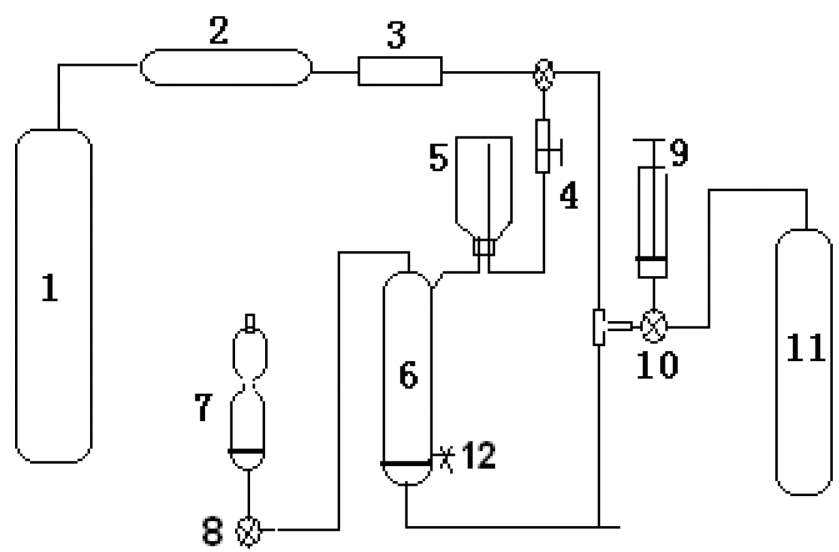

Figure 1. The purge-and-trap system for the determination of dissolved nitric oxide in seawater. The components include N2 gas (1), deoxygenation tube (2), glass rotameter (3), 2-port valve (4), sample vial (5), degassing column (6), reaction chamber (7), 3-port valves (8 and 10), gas-tight syringe (9), NO standard gas (11), and drain port (12).

gas port at the bottom of the degassing column where the high-purity $\mathrm{N}_{2}$ purge gas (1) $(99.999 \%$, Qingdao Heli Industry Gas Center, China) or a NO standard gas mixture (11) (5.4 ppmv, NO / $\mathrm{N}_{2}$ ) (Beijing Sida Standard Substance Co., China) is introduced, (b) a drain port (12) as outlet for water samples, (c) an inlet port where water samples (5) are pushed into the degassing column with $\mathrm{N}_{2}$ via a two-port valve (4), and (d) an outlet port on the top of the degassing column connected with the reaction chamber (7) via a three-port valve (8).

The NO standard gas cylinder is linked to the degassing column via a gas-tight syringe (9) (Shanghai Anting Injector Co., China). The $\mathrm{N}_{2}$ gas cylinder is connected to the degassing column via a deoxygen tube (2) (Agilent Technologies, USA) to remove traces of $\mathrm{O}_{2}$ and a glass rotameter (3) to monitor the gas flow $\left(0.1-1 \mathrm{~L} \mathrm{~min}^{-1}\right.$, Jiangyin, China). These two gas streams enter the degassing column via the port at the bottom of the flask, controlled by a three-port valve (10). The tubing used is made of polytetrafluoroethylene (PTFE, tubing $1 / 8$ in. outer diameter). Moreover, an ultraviolet-visible spectrophotometer (UV-2550, Shimadzu Co., Japan) and an automatic analytical balance (Beijing Sartorius Co., China) were used in this work.

The degassing column, reaction chamber, and the syringe were degreased with organic solvents and rinsed several times with methanol and distilled water in order to minimize potential contamination and adsorption effects. The degassing column was initially cleaned with detergent, rinsed with water, acetone, methanol, and distilled water and then treated for $30 \mathrm{~min}$ with $10 \%(v / v) \mathrm{HCl}$ in an ultrasonic bath, followed by rinsing with distilled water. Subsequently, those parts of the setup which come into contact with the sample solutions were rinsed with methanol, water, $\mathrm{HCl}$ solu- 
tion, and dilute $\mathrm{NaOH}$ solution. No significant difference was found from the test of the setup loaded with a water sample and without a water sample (dry run).

\subsection{Preparation of DAN and NO solutions}

A 2,3-diaminonaphthalene (DAN, $\geq 95 \%$, GC, SigmaAldrich Chemical Co., USA) stock solution was prepared fresh with a concentration of $10 \mathrm{mmol} \mathrm{L}^{-1}$ in dimethylformamide (Sigma-Aldrich Chemical Co., USA) and kept in the dark at $-21{ }^{\circ} \mathrm{C}$ until used. DAN solutions of $40 \mu \mathrm{mol} \mathrm{L}-1$ were prepared from the stock solution in Milli-Q water, $10 \mathrm{mmol} \mathrm{L}^{-1} \mathrm{NaOH}$ aqueous solution, and filtered natural seawater. Natural seawater was sampled from the coastal waters off Qingdao and was filtered through a $0.45 \mu \mathrm{m}$ acetate cellulose membrane (Millipore, USA). The DAN solutions were purged with $\mathrm{N}_{2}$ gas for $30 \mathrm{~min}$ to remove oxygen $\left(\mathrm{O}_{2}\right)$, then stored on ice and transferred to a refrigerator at $4{ }^{\circ} \mathrm{C}$ before use.

An aliquot of $10 \mathrm{~mL}$ Milli-Q water was bubbled with $\mathrm{N}_{2}$ gas at a flow of $10 \mathrm{~mL} \mathrm{~min}^{-1}$ for $1 \mathrm{~h}$ to remove $\mathrm{O}_{2}$ after 10 min of ultrasonic degassing. The solution was then bubbled with high-purity NO gas $(99.9 \%$, Dalian Date Gas Ltd., China) for $30 \mathrm{~min}$. The concentration of the saturated NO stock solution was $1.4 \mathrm{mmol} \mathrm{L}^{-1}$, which could be used within $3 \mathrm{~h}$ (Lantoine et al., 1995). A series of diluted NO solutions were prepared in $\mathrm{N}_{2}$-purged water from the $\mathrm{NO}$ stock solution using a syringe (Xing et al., 2005).

\subsection{Fluorometric detection of NO}

DAN reacts with $\mathrm{NO}_{x}\left(\mathrm{NO}+\mathrm{NO}_{2}\right)$ in an alkaline medium and thus forms the highly fluorescent 2,3-naphthotriazole (NAT) as follows:

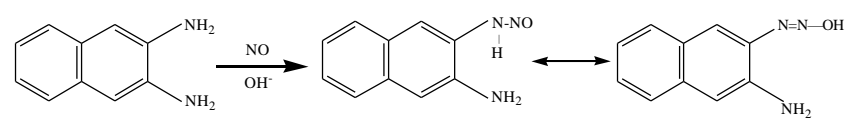

2,3-Diaminonaphthalene (DAN)

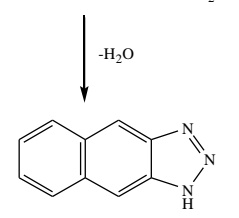

2,3-Naphthotriazole (NAT)

The reaction of $\mathrm{NO}$ and $\mathrm{O}_{2}$ with 2,3-diaminonaphthalene (DAN) produced a fluorescent triazole. Although the mechanism of this fluorescence has not yet been established in detail, the fluorescence was reported to increase dosedependently by NO addition (Nakatsubo et al., 1998). In seawater samples, the concentration of $\mathrm{O}_{2}\left(10^{-4} \mathrm{M}\right.$ order of magnitude) was far higher than that of NO $\left(10^{-10} M\right.$ order of magnitude). Both of them were stripped out and reached the DAN solution finally; thus, the NO in samples could almost quantitatively transform into NAT. Based on this reaction, a fluorometric method was originally developed for the detection of NO in oxygenated media (Misko et al., 1993; Miles et al., 1995) and has been adapted to detect NO in seawater medium instead of aqueous $\mathrm{NaOH}$ medium. Our experiments showed that the DAN solution was stable for $12 \mathrm{~h}$ and the NAT solution did not change within $4 \mathrm{~h}$. The wavelength for NAT excitement is $383 \mathrm{~nm}$ and the NAT emission is monitored at a wavelength of $410 \mathrm{~nm}$ (Liu et al., 2009).

\subsection{The influence of nitrite in seawater on the reaction of DAN and NO}

$\mathrm{NO}$ can be formed from nitrite $\left(\mathrm{NO}_{2}^{-}\right)$in seawater (Zafiriou and McFarland, 1981). Therefore, we tested a potential interference of dissolved $\mathrm{NO}_{2}^{-}$by adding different concentrations of $\mathrm{NO}_{2}^{-}$to seawater samples. The tests were conducted in the dark or with ultraviolet B (UV-B) radiation (HR $1 \times 18 w$, Xinghui Electric Instrument Factory, China). The final concentrations of $\mathrm{NO}_{2}^{-}$in the seawater samples were set to 40 , $80,120,160$, and $200 \mu \mathrm{mol} \mathrm{L}^{-1}$, and the reaction time was 1 or $12 \mathrm{~h}$.

\subsection{Sampling and analysis}

Sampling was conducted aboard the R/V Dong Fang Hong 2 on a cruise to the coastal waters off Qingdao and Jiaozhou Bay from 4 to 6 November 2009. The locations of sampling stations are shown in Fig. 2. The surface seawater samples were collected from a depth of $1 \mathrm{~m}$ at 11 stations using $8 \mathrm{~L}$ Niskin bottles mounted on a Sea-Bird CTD rosette (Sea-Bird Electronics, Inc., USA). A time-course observation of $24 \mathrm{~h}$ was carried out at station S10 near the mouth of Jiaozhou Bay (see Fig. 2).

A $500 \mathrm{~mL}$ Wheaton glass serum bottle was rinsed with the seawater three times before it was filled with seawater quickly through a siphon. When the overflowed sample reached the half volume of the bottle, the siphon was withdrawn rapidly and $0.5 \mathrm{~mL}$ of saturated $\mathrm{HgCl}_{2}$ solution was added to stop biological activities and the bottle was sealed quickly. All glass bottles were covered with aluminum foil to prevent $\mathrm{NO}_{2}^{-}$photolysis during sampling.

Because NO reacts with $\mathrm{O}_{2}$ both in the gas phase and in aqueous solution, we purged our setup for $1 \mathrm{~h}$ with $\mathrm{N}_{2}$ gas and sealed it before the measurements. In a first step, a certain amount of standard NO gas was transferred to the reaction chamber via the degassing column by injecting it from a gas-tight syringe into the $\mathrm{N}_{2}$ carrier gas stream. In the reaction chamber NO reacts with the DAN solution. After the measurement of the $\mathrm{NO}$ gas standard, a $500 \mathrm{~mL}$ seawater sample was injected into the degassing column and purged with $\mathrm{N}_{2}$ gas and immediately transferred into the reaction chamber where it reacts with $10 \mathrm{~mL}$ of DAN solution. The gas flow was controlled to ensure that the reaction of $\mathrm{NO}$ with the DAN solution was completed. Finally, the fluorescence intensity of the resulting NAT solution was measured with the F-4500 fluorescence spectrophotometer. 


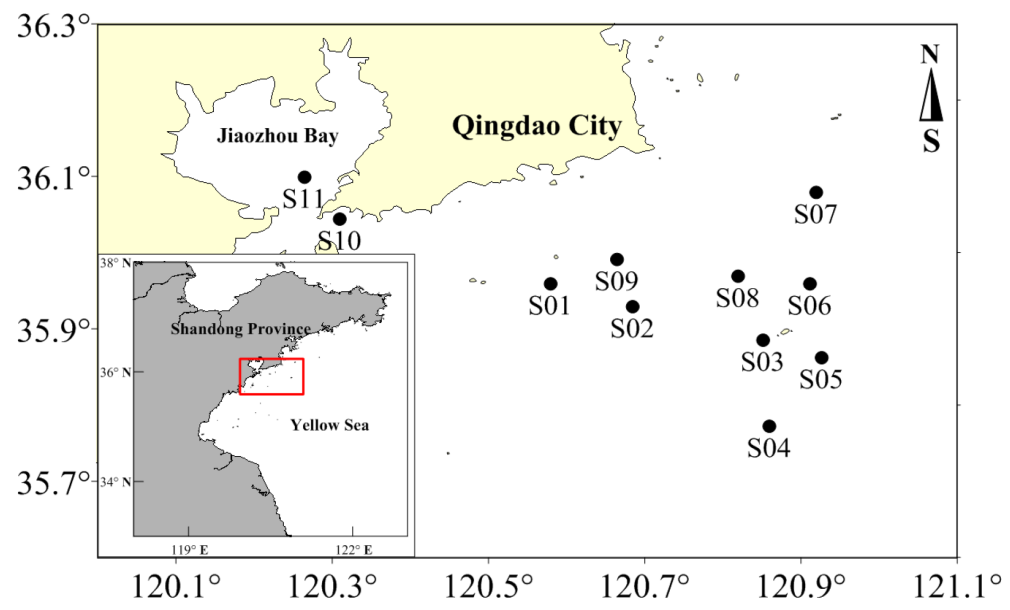

Figure 2. Locations of the sampling stations in the coastal waters off Qingdao and Jiaozhou Bay.

Table 1. The methods for NO detection in seawater.

\begin{tabular}{lrrrl}
\hline Method & $\begin{array}{r}\text { Linearity range } \\
\left(\mathrm{nmol} \mathrm{L}^{-1}\right)\end{array}$ & $\begin{array}{r}\text { Detection limit } \\
\left(\mathrm{nmol} \mathrm{L}^{-1}\right)\end{array}$ & $\begin{array}{r}\text { Analytical } \\
\text { precision }\end{array}$ & Reference \\
\hline Microelectrode & $140-9900$ & 140 & $0.24 \%$ & Zhang et al. (2003) \\
Microelectrode & $1.4-1400$ & 0.42 & $6.30 \%$ & Xing et al. (2005) \\
Microelectrode & $0.4-4000$ & 30 & - & Schreiber et al. (2008) \\
Fluorescence & $1.4-1400$ & 1.4 & $1.63 \%$ & Liu et al. (2009) \\
HPLC with fluorescence & $0.025-10$ & 0.025 & $3-5 \%$ & Olasehinde et al. (2009) \\
Purge-and-trap with chemiluminescence & - & 0.0015 & $3 \%$ & Zafiriou and McFarland (1980) \\
Purge-and-trap with chemiluminescence & - & 0.25 & $3-25 \%$ & Lutterbeck and Bange (2015) \\
Purge-and-trap with fluorescence & $0.14-19$ & 0.068 & $7.2 \%$ & This study \\
\hline
\end{tabular}

In order to prevent NO photochemical generation, the entire glass parts were wrapped with aluminum foil. The purgeand-trap procedure was conducted at a room temperature of $20^{\circ} \mathrm{C}$.

\section{6 $\mathrm{O}_{2}$, nutrients, DOC, and chlorophyll $a$ measurements}

Dissolved $\mathrm{O}_{2}$ (DO) concentrations were determined according to the Winkler method. The concentrations of dissolved nitrate, nitrite, and ammonia were measured by using an AutoAnalyzer 3 (SEAL Analytical, USA). The detection limits of the method were $0.003,0.015$, and $0.040 \mu \mathrm{mol} \mathrm{L}^{-1}$ for nitrate, nitrite, and ammonia, respectively, with the precision less than $1 \%$. The intensity of sunlight was monitored by the use of a TES-1322A actinometer (Taishi Co., Taiwan). Dissolved organic carbon (DOC) was determined by a high-temperature combustion method using a Shimadzu TOC-5000 analyzer with an Al-Pt catalyst (Shimadzu Co., Japan). The precision of the DOC measurements was less than $2 \%$. Concentrations of chlorophyll $a$ were measured with a bbe cuvette fluorometer (bbe-Moldaenke $\mathrm{GmbH}$, Kiel, Germany).

\subsection{NO production rates}

Experiments for $\mathrm{NO}$ production by $\mathrm{NO}_{2}^{-}$photolysis were conducted at station 10 as follows: aliquots of $10 \mathrm{~mL}$ untreated seawater samples from a depth of $0.2 \mathrm{~m}$ or Millipore membrane $(0.45 \mu \mathrm{m})$ filtered samples were distributed into three $14 \mathrm{~mL}$ glass vials. The initial concentrations of $\mathrm{NO}_{2}^{-}$and DOC in seawater were $0.75 \mu \mathrm{mol} \mathrm{L}^{-1}$ and $439 \mu \mathrm{mol} \mathrm{L}^{-1} \mathrm{C}$, respectively. Then $200 \mu \mathrm{L}$ of $20 \% \mathrm{NaN}_{3}$ solutions (instead of saturated $\mathrm{HgCl}_{2}$ solution to avoid contamination by the photosensitive $\mathrm{Hg}$ ) and $20 \mu \mathrm{L}$ of $1 \mathrm{mmol} \mathrm{L}^{-1}$ DAN solutions were added. The vials were sealed with rubber septa and aluminum crimp tops, and were exposed to sunlight on the deck at ambient temperature $\left(17^{\circ} \mathrm{C}\right)$ or at $13 \pm 2{ }^{\circ} \mathrm{C}$ in a water bath supplied with the ambient seawater. For "dark" controls, vials were wrapped in aluminum foil. The intensity of sunlight ranged from 67565 to $71500 /$,lx (average: $694301 x$ ). After irradiation by sunlight for $30 \mathrm{~min}$, the NO concentrations were measured with the method described above. The NO photolysis production rates were computed based on the time-dependent difference between the NO concentrations before and after irradiation. 
Table 2. Reaction yields of the reaction of DAN with NO at different flow rates and purge times.

\begin{tabular}{lrrrr}
\hline Purge flow rate & \multicolumn{4}{c}{ Reaction yield (\%) } \\
\cline { 2 - 5 }$\left(\mathrm{mL} \mathrm{min}^{-1}\right)$ & $15 \mathrm{~min}$ & $30 \mathrm{~min}$ & $45 \mathrm{~min}$ & $60 \mathrm{~min}$ \\
\hline 200 & - & - & - & - \\
300 & - & - & 21 & 34 \\
400 & 56 & 85 & 69 & 69 \\
500 & - & - & 22 & 26 \\
600 & - & - & 31 & 33 \\
\hline
\end{tabular}

We also measured NO production rates in natural seawater at station 10. Three transparent polyethylene buckets $(3.5 \mathrm{~L})$ were filled with the surface seawater from a depth of $0.2 \mathrm{~m}$. The buckets were exposed to sunlight in the water bath on deck. The experiment began at 08:30 LT (local time) and the NO production rates and chlorophyll $a$ concentrations were concurrently measured at $2 \mathrm{~h}$ intervals. An aliquot of $10 \mathrm{~mL}$ of sample was collected from each bucket using a glass syringe, distributed and sealed in a $14 \mathrm{~mL}$ glass vial, and then incubated under the same conditions as the bucket samples. Three vials per sample were used in the experiments. After $30 \mathrm{~min}$ of incubation, solutions of $20 \mu \mathrm{L}$ DAN $\left(1 \mathrm{mmol} \mathrm{L}^{-1}\right)$ were injected into the vials. Finally, concentrations of NO were detected and $\mathrm{NO}$ production rates were calculated.

\section{Results and discussion}

\subsection{Method evaluation}

$\mathrm{NO}$ is a conceptually important intermediate in N-cycle biogeochemistry, a product of ocean photochemistry, and a putative intercellular signal molecule. Unfortunately, our knowledge of oceanic NO distribution and the major pathways of NO is very poor. There are only a few published NO concentration measurements available because a reliable and easy to use method to determine dissolved NO at in situ concentrations in seawater samples is missing. We tried to find a promising method that is both convenient for laboratory and in situ observations with high sensitivity.

Both the purge time and flow of the purge gas $\left(\mathrm{N}_{2}\right)$ significantly influence the yield of the NO+DAN reaction and thus, the overall purge efficiency (see Table 2). The optimal (i.e., maximum) reaction yield was $85 \%$ after $30 \mathrm{~min}$ of purging at a flow of $400 \mathrm{~mL} \mathrm{~min}^{-1}$. The error of these measurements (in triplicate) was in the range of $8-25 \%$. As the measuring scheme is possibly not optimal yet, we may repeat the measurements with purge flow rates between 350 and $450 \mathrm{~mL} \mathrm{~min}^{-1}$, especially around $400 \mathrm{~mL} \mathrm{~min}^{-1}$. It might be possible to obtain even better results with fine tuning.

The setup was tested for internal NO production or loss by comparing the fluorescence intensity from NO-free gas or NO calibration gas passing through the degassing column with the fluorescence intensity from the same gas bypassing the degassing column. This procedure was repeated with both a dry degassing column and a moistening degassing column (by a minimum amount of filtered seawater). Neither NO production nor NO loss by adsorption was observed in the setup in all test runs.

Seawater samples from coastal waters off Qingdao were analyzed in the lab up to seven times and gave a relative standard deviation of $\pm 7.2 \%$. The detection limit of our method was determined to be $0.068 \mathrm{nmol} \mathrm{L}^{-1}(\mathrm{~S} / \mathrm{N}=3)$, which is lower than most of the reported detection limits for NO measurements in seawater (see Table 1)

The NO recovery coefficient of our purge-and-trap system was estimated by the addition of the same volume of a $\mathrm{NO}$ standard solution to (i) $500 \mathrm{~mL}$ of NO-free seawater in the degassing column and (ii) $10 \mathrm{~mL}$ of DAN solution (with a DAN concentration of $40 \mu \mathrm{mol} \mathrm{L}-1$ ) in the reaction chamber. The recovery coefficient (RC) of NO was calculated according to the following:

$\mathrm{RC}(\%)=\mathrm{NO}(\mathrm{sw}) / \mathrm{NO}(\mathrm{DAN}) \times 100 \%$,

where $\mathrm{NO}(\mathrm{DAN})$ stands for the NO directly injected to the DAN solution and $\mathrm{NO}(\mathrm{sw})$ stands for the $\mathrm{NO}$ measured from the sample in degassing column according to the method described above. The rate law obtained from the oxidation of $\mathrm{NO}$ is

$-\mathrm{d}[\mathrm{NO}] / \mathrm{d} t=4 k[\mathrm{NO}]^{2}\left[\mathrm{O}_{2}\right]$,

with $k=2 \times 10^{6} \mathrm{M}^{-2} \mathrm{~s}^{-1}$. The reaction of $\mathrm{NO}$ with $\mathrm{O}_{2}$ could consume NO in the stripping period. The NO recovery coefficients of the purge-and-trap system were evaluated and ranged from 80.2 to $90.0 \%$, with an average of $83.8 \%$. Furthermore, three replicates of in situ seawater were measured using our system and method; the aqueous NO solution did not change within $1 \mathrm{~h}$, which was also demonstrated by Lutterbeck and Bange (2015).

In order to check the linearity of our method, a $10 \mathrm{~mL}$ solution of $40 \mu \mathrm{mol} \mathrm{L}^{-1}$ DAN was injected into the reaction chamber and purged with $\mathrm{N}_{2}$ gas at a rate of $10 \mathrm{~mL} \mathrm{~min}^{-1}$ for 5 min prior to the actual measurements. A series of NOfree seawater samples placed in the degassing column were spiked with different volumes of the NO standard gas (mixing ratio $5.4 \mathrm{ppmv} \mathrm{NO} / \mathrm{N}_{2}$ ) and analyzed according to the procedure described above. The resulting fluorescence intensity was linear with the NO concentrations in the range from 0.14 to $19.0 \mathrm{nmol} \mathrm{L}^{-1}(y=7.4286 x+0.6188, R=0.9976$, $P<0.0001$ ) (Fig. 3).

The results of the samples spiked with varying concentrations of dissolved $\mathrm{NO}_{2}^{-}$are given in Fig. 4. The blank had no signal when measured with the fluorescence spectrophotometer after UV-B irradiation or after being left in the dark; that is, the NO concentrations were zero. Nitrite did not cause significant problems with natural samples during the measurement process. In general, samples with the 


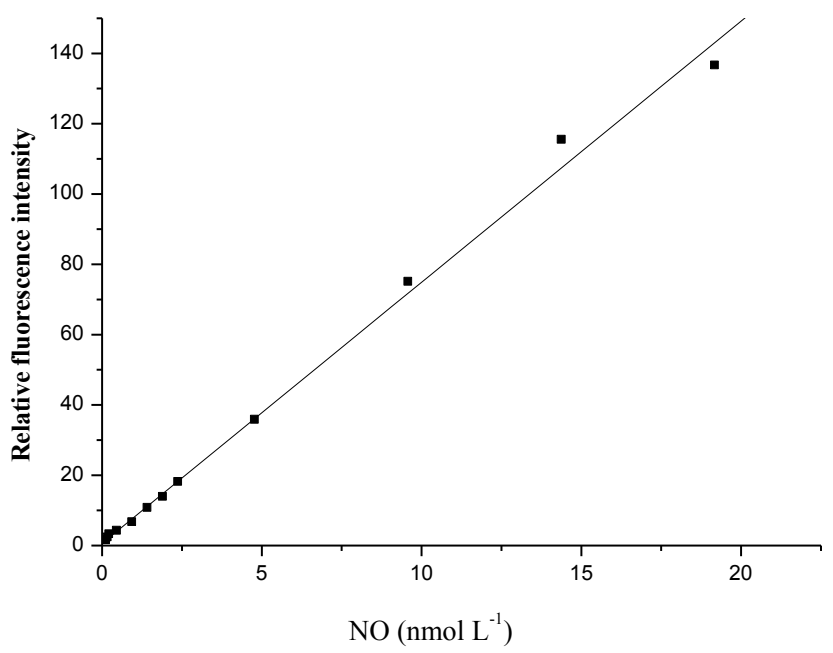

Figure 3. Relationship between nitric oxide concentrations and fluorescence intensities.

same $\mathrm{NO}_{2}^{-}$concentration showed higher fluorescence when UV irradiated or kept in the dark for $12 \mathrm{~h}$ compared to samples under short-term (i.e., $1 \mathrm{~h}$ ) UV irradiation or kept in the dark. This points to a significant NO production under UV irradiation $\left(n=5, F=76.13, p=2.32 \times 10^{-5}\right)$ and (albeit weaker) $\mathrm{NO}$ dark production from $\mathrm{NO}_{2}^{-}$. Higher $\mathrm{NO}_{2}^{-}$concentrations resulted in a slight increase in fluorescence when irradiated. Therefore, we conclude that the measurements of NO should be done in the dark as soon as possible after sampling when high $\mathrm{NO}_{2}^{-}$concentrations occur. Here, these high $\mathrm{NO}_{2}^{-}$concentrations were used to demonstrate no obvious effect caused by $\mathrm{NO}_{2}^{-}$on the detection method; thus, low concentrations of $\mathrm{NO}_{2}^{-}$also do not affect this method. On the other hand, the fluorescence intensity could not be detected with low concentrations of $\mathrm{NO}_{2}^{-}$.

To assess the influence of the interferences of dissolved organic matter, trace metals, nutrients, and other substances in seawater, the NO-fluorescence intensity relationship should be determined when the method is applied in different oceanic regions.

With our method, we are able to detect $>0.068 \mathrm{nmol} \mathrm{L}^{-1}$ NO in discrete seawater samples with a volume of $500 \mathrm{~mL}$. With a larger degassing column, even lower concentrations of NO might be determined.

A U-shaped tube and cold bath (i.e., a water trap) was initially placed between the degassing column and the reaction chamber in order to eliminate small amounts of water carried by the $\mathrm{N}_{2}$ gas stream. However, we found that the fluorescence intensities did not show significant differences when the water trap was removed.

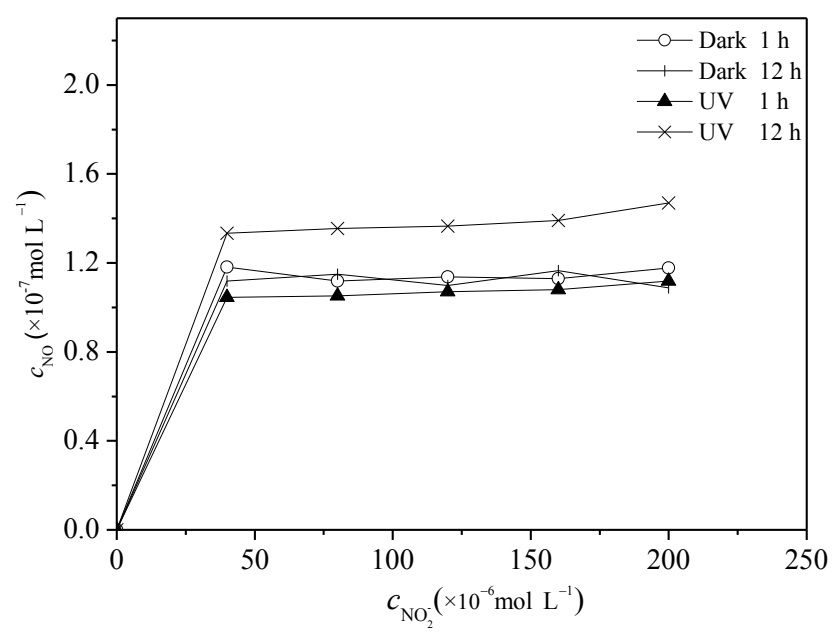

Figure 4. The fluorescence variations of NAT in seawater with different concentrations of nitrite in the dark or under UV-B radiation.

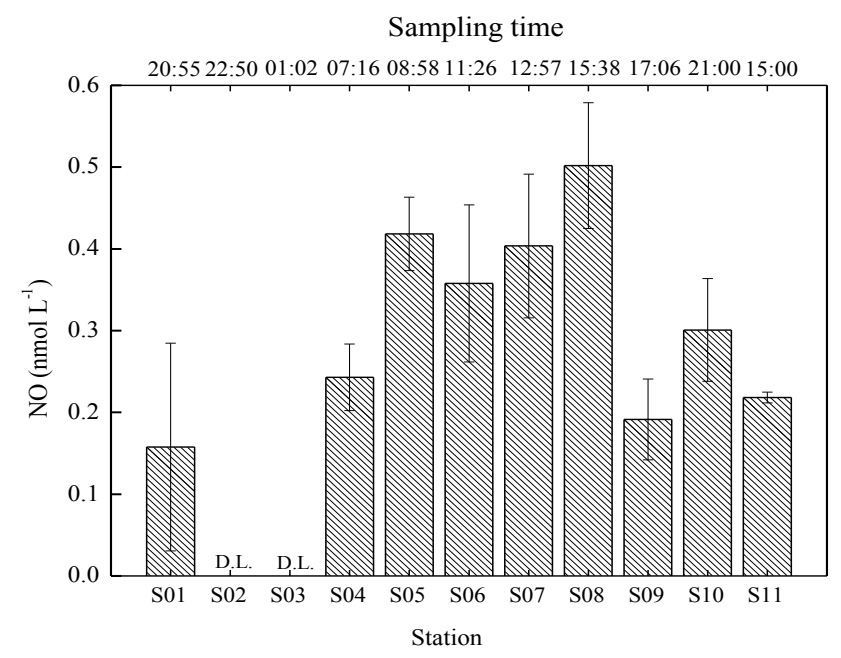

Figure 5. The concentrations of NO in the surface water off Qingdao and Jiaozhou Bay.

\subsection{Distribution of dissolved NO in coastal waters of Qingdao}

Figure 5 shows the NO concentrations of surface seawater in coastal waters off Qingdao (stations S01-S09) and in the Jiaozhou Bay (stations S10 and S11). The concentrations of NO ranged from below the detection limit (D.L., stat. 02 and 03 ) up to $0.50 \pm 0.01 \mathrm{nmol} \mathrm{L}^{-1}$ (stat. S08), with an overall mean of $0.26 \pm 0.14 \mathrm{nmol} \mathrm{L}^{-1}$. It is noteworthy that the higher NO concentrations seem to be related to the time point of sampling (given in local time, LT): samples of stations S02 and S03 were collected at nighttime at 22:30 and 00:50 LT, respectively, while samples for stations $\mathrm{S} 05, \mathrm{~S} 06, \mathrm{~S} 07$, and S08 were collected during the daytime (08:58-15:38 LT). (Stations S09 and S10 have been measured in Jiaozhou Bay and, thus, their NO concentrations are not directly compara- 


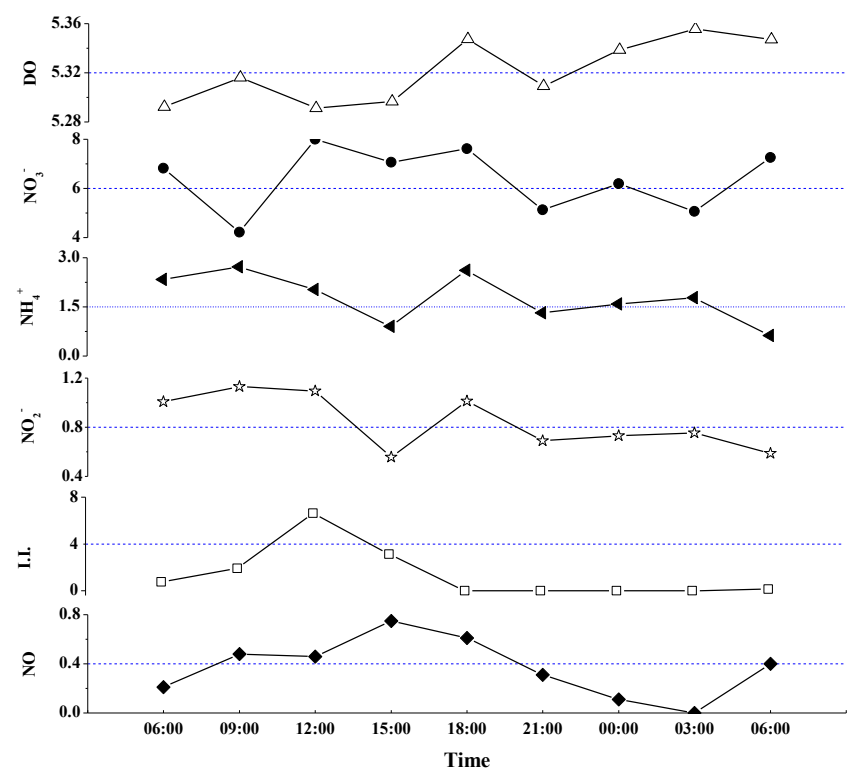

Figure 6. The diurnal variations in NO concentrations and related parameters in the surface seawater at station 10.

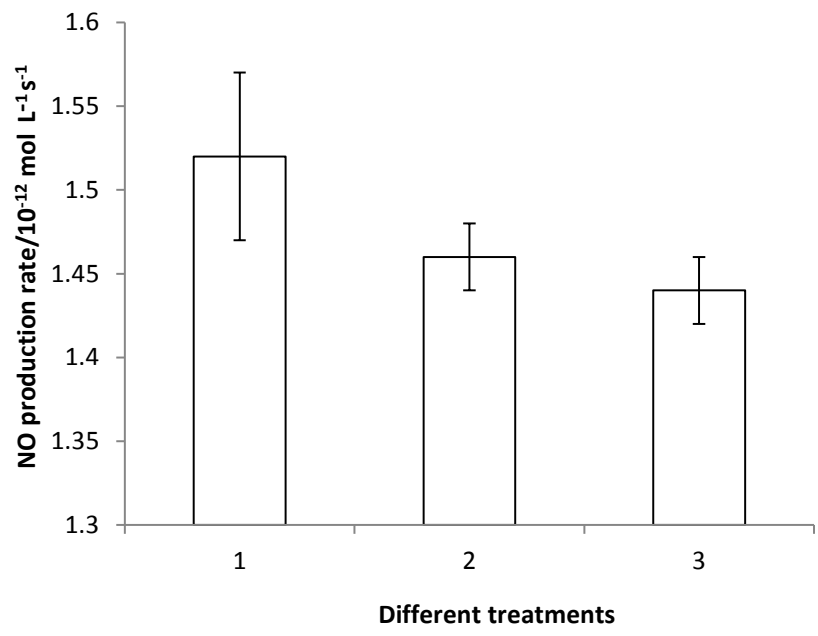

Figure 7. The production rates of NO by seawater irradiation under natural light after different treatments. Treatment 1 is seawater irradiation at an ambient temperature of $17^{\circ} \mathrm{C}$, treatment 2 is $0.45 \mu \mathrm{m}$ Millipore filtered samples, and treatment 3 is the incubation of nonfiltered samples in a water bath at $13{ }^{\circ} \mathrm{C}$.

ble with the stations off Qingdao.) Our results are generally consistent with the findings in the aquatic ecosystem of Daya Bay in China (Zhang et al., 2006) and the nitrite-rich surface waters of the central equatorial Pacific Ocean (Zafiriou et al., 1980), indicating that sunlight could be a main factor affecting $\mathrm{NO}$ formation in seawater. The concentrations of $\mathrm{NO}$ in coastal surface waters off Qingdao were found to be an order of magnitude higher than those in surface waters during daytime in the central equatorial Pacific Ocean $\left(0.05 \mathrm{nmol} \mathrm{L}^{-1}\right)$ (Zafiriou et al., 1980; Zafiriou and McFarland, 1981). This
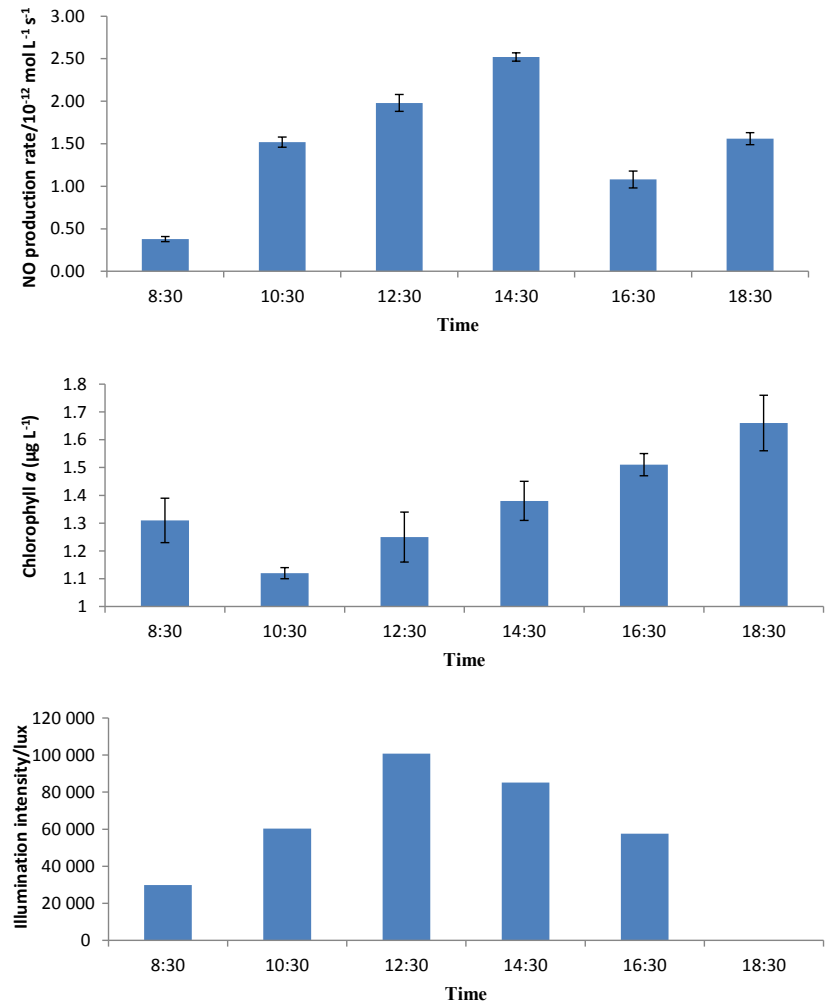

Figure 8. The variation in NO production rates, chlorophyll $a$ concentrations, and sunlight intensities in the incubation experiments using Qingdao coastal water.

difference is probably related to the concentrations of $\mathrm{NO}_{2}^{-}$ in seawater. Zafiriou et al. (1980) proposed that sunlight photolyzes $\mathrm{NO}_{2}^{-}$in surface water by the following reaction:

$\mathrm{NO}_{2}^{-}+\mathrm{H}_{2} \mathrm{O} \stackrel{h v}{\longrightarrow} \mathrm{NO}+\cdot \mathrm{OH}+\mathrm{OH}^{-}$.

According to the reaction above, high concentrations of $\mathrm{NO}_{2}^{-}$together with strong solar irradiation could cause enhanced concentrations of NO in seawater. The sunlight intensity of the central equatorial Pacific is generally higher than that of coastal waters off Qingdao (located at $36^{\circ} 05^{\prime} \mathrm{N}$ ); however, the coastal waters off Qingdao at the time of our measurements exhibited an average $\mathrm{NO}_{2}^{-}$concentration of $0.49 \pm 0.25 \mu \mathrm{mol} \mathrm{L}{ }^{-1}$, which was much higher than that observed in the central equatorial Pacific Ocean $\left(\sim 0.1 \mu \mathrm{mol} \mathrm{L}{ }^{-1}\right)$.

NO is a short-lived intermediate of various microbial processes of the nitrogen cycle, which is involved in denitrification (Kampschreur et al., 2007), anammox (Kartal et al., 2011), and archaea ammonia-oxidizing processes (MartensHabbena et al., 2015). Zafiriou and McFarland (1981) analyzed NO in seawater samples at the sea surface of the central equatorial Pacific by stripping $\mathrm{NO}$ into an air and $\mathrm{N}_{2}$ stream by passing it through the chemiluminescence-type detector. Thus, the NO concentrations were underestimated 
to some extent because seawater samples were suboxic or anoxic. However, time-dependent losses from microbial processes were minimized. Lutterbeck and Bange (2015) improved the method above to determine dissolved NO in discrete seawater samples of the eastern tropical South Pacific Ocean. The contamination by $\mathrm{O}_{2}$ diffusion into the continuous samples could be further minimized. This work was also designed to detect dissolved NO in discrete seawater samples with a combination of a purge-and-trap setup and a fluorometric $\mathrm{NO}$ analyzer. The $\mathrm{HgCl}_{2}$ solution was added to stop biological activities during the stripping. However, the disposal of these Hg-contaminated solutions is a tough proposition. To improve the method, the purge-and-trap setup could be modified and the stripping time could be reduced, then the addition of $\mathrm{HgCl}_{2}$ solution may be removed in the future.

The diurnal variation in NO concentrations and other parameters in surface seawater for station 10 are shown in Fig. 6. Concentrations of NO presented a significant diurnal variation within $24 \mathrm{~h}$. The peak value appeared at 15:00 LT with a concentration of $0.81 \mathrm{nmol} \mathrm{L}^{-1}$. After that, the concentration of NO decreased with time gradually until a minimum value occurred at 03:00. Obviously, the concentration of dissolved $\mathrm{NO}$ at this station was influenced by the in situ sunlight intensity. However, the maximum NO concentration appeared not at 12:00 but at 15:00 LT, which suggested that there were other influencing factors besides sunlight irradiation.

\subsection{NO production rates in coastal waters}

The results of the NO irradiation experiments are given in Fig. 7. The production rate of NO through seawater irradiation was $1.52 \times 10^{-12} \mathrm{~mol} \mathrm{~L}^{-1} \mathrm{~s}^{-1}$, which is slightly higher than the NO production rate of the $0.45 \mu \mathrm{m}$ Millipore filtered samples $\left(1.46 \times 10^{-12} \mathrm{~mol} \mathrm{~L}^{-1} \mathrm{~s}^{-1}\right)$. The difference may indicate that particles in seawater could increase the NO production rate. The non-filtered samples incubated in the water bath had a lower NO production rate $\left(1.44 \times 10^{-12} \mathrm{~mol} \mathrm{~L}^{-1} \mathrm{~s}^{-1}\right)$ compared to the other nonfiltered treatment, which could be ascribed to the difference of the temperature. The ambient temperature and water bath were 17 and $13{ }^{\circ} \mathrm{C}$, respectively; thus, the higher temperature may have resulted in a higher photolysis rate. The photochemical production rates of NO in Qingdao coastal waters during the daytime were generally higher than those reported from the central equatorial Pacific Ocean (0.4$1.2 \times 10^{-12} \mathrm{~mol} \mathrm{~L}^{-1} \mathrm{~s}^{-1}$ ) (Zafiriou and McFarland, 1981).

Previous experiments about $\mathrm{NO}_{2}^{-}$photolysis were also carried out in our laboratory ( $\mathrm{Li}$ et al., 2011): the production of NO was observed after $3 \mathrm{~h}$ illumination of 10 $100 \mu \mathrm{mol} \mathrm{L}{ }^{-1} \mathrm{NO}_{2}^{-}$solutions in Milli-Q water. There was an increasing trend of $\mathrm{NO}$ concentrations with the $\mathrm{NO}_{2}^{-}$concentrations. For natural seawater, it was observed to have an increasing trend of $\mathrm{NO}$ concentration with the illumination time (Li et al., 2011). The process of sunlight photolysis of
$\mathrm{NO}_{2}^{-}$in surface water was demonstrated, which was consistent with the results of Zafiriou et al. (1980) and Olasehinde et al. (2009).

The production and consumption of NO occur synchronously when sunlight photolyzes natural seawater. During the photolysis of $\mathrm{NO}_{2}^{-}$, mainly $\mathrm{NO}$ and $\mathrm{OH}$ are produced. On the other hand, the loss of NO happens by forming NO-reactive radicals from coloured dissolved organic matter (CDOM) (Zafiriou et al., 1990; Zafiriou and Dister, 1991; Olasehinde et al., 2009). The concentration of NO after exposure to sunlight is a balancing of this production against consumption by radical recombination. The study area has high concentrations of DOC and is rich in CDOM (Liu et al., 2010; Yang et al., 2011). Light might also induce NO losses by forming NO-reactive radicals from CDOM in irradiated waters during the irradiation experiments. Thus, the authentic $\mathrm{NO}$ resulting from $\mathrm{NO}_{2}^{-}$photolysis was underestimated. The photochemical production rates of NO were only a total value of production and consumption in this study.

The on-deck incubation experiments for the production rates of NO in Qingdao coastal waters, together with chlorophyll $a$ concentrations and sunlight intensities, are shown in Fig. 8. The production rates of NO exhibited a clear variation during the course of the day with a maximum value appearing at 14:30 LT. The maximum value of $2.52 \times 10^{-12} \mathrm{~mol} \mathrm{~L}^{-1} \mathrm{~s}^{-1}$ was about 7-fold higher than the minimum value at 08:30 LT. The production rates of NO kept an increasing trend from 08:30 to 14:30 LT. The mean production rate in Qingdao coastal waters was $1.51 \times 10^{-12} \mathrm{~mol} \mathrm{~L}^{-1} \mathrm{~s}^{-1}$ during the day. The variation in the production rates of NO did not follow the trends in chlorophyll $a$ concentrations and solar radiation. Therefore, the production pattern of $\mathrm{NO}$ in marine environments deserves further research.

\section{Summary}

For the determination of NO concentrations in discrete seawater samples we developed a new method by combining a purge-and-trap setup with fluorometric detection of NO. The method showed a linear fluorescence intensity for NO concentrations ranging from 0.14 to $19 \mathrm{nmol} \mathrm{L}^{-1}$. The detection limit is $0.068 \mathrm{nmol} \mathrm{L}^{-1}(\mathrm{~S} / \mathrm{N}=3)$, the average recovery coefficient is $83.8 \%(80.2-90.0 \%)$, and the relative standard deviation is $\pm 7.2 \%$. Our method was applied to measure concentrations of NO in the surface layer of the coastal waters off Qingdao and Jiaozhou Bay. NO concentrations varied from below the detection limit to $0.50 \mathrm{nmol} \mathrm{L}^{-1}$, with an average of $0.26 \pm 0.14 \mathrm{nmol} \mathrm{L}^{-1}$. The concentrations of $\mathrm{NO}$ in coastal waters off Qingdao were an order of magnitude higher than those in surface waters of the central equatorial Pacific. NO surface concentrations were generally enhanced significantly during daytime, implying that NO formation processes such as $\mathrm{NO}_{2}^{-}$photolysis are much higher 
during daytime than chemical NO consumption, which, in turn, leads to the observed significant decrease in the NO concentrations during nighttime. The measurements of NO production rates showed that the occurrence of particles and an increase in temperature can enhance NO production.

We conclude that our method can be applied to measure (i) NO concentrations in the ocean surface, (ii) NO production and consumption pathways in oceanic waters, and (iii) NO production rates in biological culture experiments.

Data availability. No data sets were used in this article.

Competing interests. The authors declare that they have no conflict of interest.

Acknowledgements. We thank Li Tie and Zhu Chenjian for their assistance during sample collection. This research was supported by the National Natural Science Foundation of China (no. 41676065), the National Key Research and Development Program of China (grant no. 2016YFA0601301), the Fundamental Research Funds for the Central Universities (no. 201564015), and Aoshan Talents Program supported by Qingdao National Laboratory for Marine Science and Technology (no. 2015ASTP). We also thank two anonymous reviewers for their constructive comments, which greatly improved the manuscript.

Edited by: Mario Hoppema

Reviewed by: two anonymous referees

\section{References}

Bange, H. W.: Chapter 2 - Gaseous Nitrogen Compounds (NO, $\mathrm{N}_{2} \mathrm{O}, \mathrm{N}_{2}, \mathrm{NH}_{3}$ ) in the Ocean in: Nitrogen in the Marine Environment, Second Edn., Elsevier, Amsterdam, the Netherlands, 51-94, 2008.

Canfield, D. E., Glazer, A. N., and Falkowski, P. G.: The evolution and future of the Earth's nitrogen cycle, Science, 330, 192-196, 2010.

Chen, J., Wu, F. H., Xiao, Q., Yang, Z. H., Huang, S. K., Wang, J., Wu, Y. G., Dong, X. J., Pei, Z. M., and Zhen, H. L.: Diurnal variation of nitric oxide emission flux from a mangrove wetland in Zhangjiang River Estuary, China, Estuar. Coast. Shelf S., 90, 212-220, 2010.

Hetrick, E. M. and Schoenfisch, M. H.: Analytical chemistry of nitric oxide, Annu. Rev. Anal. Chem., 2, 409-433, 2009.

Kampschreur, M. J., Picioreanu, C., Tan, N., Kleerebezem, R., Jetten, M. S. M., and van Loosdrecht, M. C. M.: Unraveling the source of nitric oxide emission during nitrification, Water Environ. Res., 79, 2499-2509, 2007.

Kartal, B., Maalcke, W. J., de Almeida, N. M., Cirpus, I., Gloerich, J., Geert, S. W., den Camp, H., Harhangi, H. R., Janssen-Megens, E. M., Francoijs, K. J., Stunnenberg, H. G., Keltjens, J. T., Jetten, M. S. M., and Strous, M.: Molecular mechanism of anaerobic ammonium oxidation, Nature, 479, 127-130, 2011.
Lantoine, F., Trevin, S., Bedioui, F., and Devynck. J.: Selective and sensitive electrochemical measurement of nitric oxide in aqueous solution: discussion and new results, J. Electroanal. Chem., 392, 85-89, 1995.

Law, C. S.: Air-Sea Transfer: $\mathrm{N}_{2} \mathrm{O}, \mathrm{NO}, \mathrm{CH}_{4}, \mathrm{CO}$, edited by: Steele, J. H., Thorpe, S. A., and Turekian, K. K., Encyclopedia of Ocean Sciences, Academic Press, San Diego, USA, 137-143, 2001.

Lee, D. S., Köhler, I., Grobler, E., Rohrer, F., Sausen, R., GallardoKlenner, L., Olivier, J. G. J., Dentener, F. J., and Bouwman. A. F.: Estimations of global no, emissions and their uncertainties, Atmos. Environ., 31, 1735-1749, 1997.

Li, P. F., Li, W. S., Liu, C. Y., Zhu, X. C., and Zhang, Q.: The Photodecomposition of Nitrite in Water, Environ. Chem., 30, 18831888, 2011 (in Chinese with English abstract).

Liu, C. Y., Zhang, Z. B., Xing, L., Lin, C., and Wu, Z. Z.: The ocean biogeochemistry of nitric oxide, Periodical of Ocean University of China, 34(sup), 16-22, 2004 (in Chinese with English abstract).

Liu, C. Y., Zhang, Z. B., and Chen, X. R.: The mutual effects of nitric oxide and iron on the growth of marine algae, Acta Oceanol. Sin., 24, 100-109, 2005.

Liu, C. Y., Zhang, Z. B., Li, P. F., and Huang, H. W.: Growth effect of exogenous nitric oxide on Platymonas subcordiforms and spectrum study, Chinese J. Environ. Sci., 27, 1062-1067, 2006 (in Chinese with English abstract).

Liu, C. Y., Zhao, M., Ren, C. Y., Yang, G. P., Li, P. F., and Han, Y.: Direct measurement of nitric oxide in seawater medium by fluorometric method. Chinese J. Anal. Chem., 37, 1463-1467, 2009.

Liu, C. Y., Yang, X. M., Yang, G. P., Zhou, L. M., and Li, P. F. Composition and characterization of colloidal organic matter in the coastal surface waters of Qingdao, China, Mar. Chem., 121, 123-131, 2010.

Liu, C. Y., Kieber, D. J., Yang, G. P., Xue, C., Wang, L. L., and Liu, H. H.: Evidence for the mutual effects of dimethylsulfoniopropionate and nitric oxide during the growth of marine microalgae, Nitric Oxide, 42, 54-61, 2014.

Lutterbeck, H. E. and Bange, H. W.: An improved method for the determination of dissolved nitric oxide (NO) in seawater samples, Ocean Sci., 11, 937-946, https://doi.org/10.5194/os-11937-2015, 2015.

Martens-Habbena, W., Qin, W., Horak, R. E., Urakawa, H., Schauer, A. J., Moffett, J. W., Armbrust, E. V., Ingalls, A. E., Devol, A. H., and Stahl, D. A.: The production of nitric oxide by marine ammonia-oxidizing archaea and inhibition of archaeal ammonia oxidation by a nitric oxide scavenger, Environ. Microbiol., 17, 2261-1274, https://doi.org/10.1111/1462-2920.12677, 2015.

Mazzeo, N. A., Venegas, L. E., and Choren, H.: Analysis of NO, $\mathrm{NO}_{2}, \mathrm{O}_{3}$ and $\mathrm{NO}_{X}$ concentrations measured at a green area of Buenos Aires City during wintertime, Atmos. Environ., 39, 3055-3068, 2005.

Miles, A. M., Chen, Y., Owens, M. W., and Grisham, M. B.: Fluorometric determination of nitric oxide, in: Methods: A Companion to Methods in Enzymology, 7, 40-47, 1995.

Misko, T. P., Schilling, R. J., Salvemini, D., Moore, W. M., and Currie, M. G.: A fluorometric assay for the measurement of nitrite in biological samples, Anal. Biochem., 214, 11-16, 1993.

Nakatsubo, N., Kojima, H., Sakurai, K., Kikuchi, K., Nagoshi, H., Hirata, Y., Akaike, T., Maeda, H., Urano, Y., Higuchi, 
T., and Nagano, T.: Improved nitric oxide detection using 2,3diaminonaphthalene and its application to the evaluation of novel nitric oxide synthase inhibitors, Biol. Pharm. Bull., 21, 12471250, 1998.

Olasehinde, E. F., Takeda, K., and Sakugawa, H.: Development of an analytical method for nitric oxide radical determination in natural waters, Anal. Chem., 81, 6843-6850, 2009.

Schreiber, F., Polerecky, L., and de Beer, D.: Nitric oxide microsensor for high spatial resolution measurements in biofilms and sediments, Anal. Chem., 80, 1152-1158, https://doi.org/10.1021/ac071563x, 2008.

Schreiber, F., Wunderlich, P., Udert, K. M., and Wells, G.F.: Nitric oxide and nitrous oxide turnover in natural and engineered microbial communities: biological pathways, chemical reactions, and novel technologies, Front. Microbiol., 3, 372, https://doi.org/10.3389/fmicb.2012.00372, 2012.

Thamdrup, B.: New pathways and processes in the global nitrogen cycle, Annu. Rev. Ecol. Evol. S., 43, 407-428, 2012.

Voss, M., Bange, H. W., Joachim, W. D., Middelburg, J. J., Montoya, J. P., and Ward, B.: The marine nitrogen cycle: recent discoveries, uncertainties and the potential relevance of climate change, Philos. T. R. Soc. B, 368, 20130121, https://doi.org/10.1098/rstb.2013.0121, 2013.

Ward, B. B. and Zafiriou, O. C.: Nitrification and nitric oxide in the oxygen minimum of the eastern tropical North Pacific, Deep-Sea Res., 35, 1127-1142, 1988.

Williams, E. J., Hutchinson, G. L., and Fehsenfeld, F. C.: $\mathrm{NO}_{x}$ and $\mathrm{N}_{2} \mathrm{O}$ emissions from soil, Global Biogeochem. Cy., 6, 351-388, 1992.

Xing, L., Zhang, Z. B., Liu, C. Y., Wu, Z. Z., and Lin, C.: Amperometric detection of nitric oxide with microsensor in the medium of seawater and its applications, Sensors, 5, 537-545, 2005.
Yang, G. P., Ren, C. Y., Lu, X. L., Liu, C. Y., and Ding, H. B.: Distribution, flux and photoproduction of carbon monoxide in the East China Sea and the Yellow Sea in spring, J. Geophys. Res., 116, C02001, https://doi.org/10.1029/2010JC006300, 2011.

Zafiriou, O. C. and Dister, B.: Photochemical free radical production rates: Gulf of Maine and Woods Hole-Miami transect, J. Geophys. Res., 96, 4939-4945, 1991.

Zafiriou, O. C. and McFarland, M.: Determination of trace levels of nitric oxide in aqueous solution, Anal. Chem., 52, 1662-1667, 1980.

Zafiriou, O. C. and McFarland, M.: Nitric oxide from nitrite photolysis in the central equatorial Pacific, J. Geophys. Res., 86, 3173 3182, 1981.

Zafiriou, O. C., McFarland, M., and Bromund, R. H.: Nitric oxide in seawater, Science, 207, 637-639, 1980.

Zafiriou, O. C., Blough, N. V., Dister, B., Kieber, D., and Moffett, J.: Molecular probe systems for reactive transients in natural waters, Mar. Chem., 30, 45-71, 1990.

Zehr, J. P. and Ward, B. B.: Nitrogen cycling in the ocean: New perspectives on processes and paradigms, Appl. Environ. Microb., 68, 1015-1024, 2002.

Zhang, Z. B., Lin, C., Liu, C. Y., Xing, L., Wu, Z. Z., and Sun, F.: Study on patterns and chemical features of $\mathrm{NO}$ effect on marine phytoplankton growth, Sci. China Ser. B, 48, 376-384, 2005.

Zhang, Z. B., Liu, C. Y., Wu, Z. Z., Xing, L., and Li, P. F.: Detection of nitric oxide in culture media and studies on nitric oxide formation by marine microalgae, Med. Sci. Monitor., 12, 75-85, 2006.

Zhang, Z. B., Xing, L., Wu, Z. Z., Liu, C. Y., Lin, C., and Liu, L. S.: Discovery of nitric oxide in marine ecological system and the chemical characteristics of nitric oxide, Sci. China Ser. B, 49, 475-480, 2006. 